\title{
A IMPORTÂNCIA DO PROFESSOR PESQUISADOR
}

\section{LA IMPORTANCIA DEL PROFESOR INVESTIGADOR}

\section{THE IMPORTANCE OF THE RESEARCH TEACHER}

\author{
Carla Silva Tormam 1 \\ Paula Trindade da Silva Selbach2
}

\begin{abstract}
Resumo
Este artigo tem como objetivo realizar reflexões acerca da importância do papel do professor pesquisador, com o intuito de evidenciar o engajamento do professor enquanto agente pesquisador, tornando-se fundamental para que este desempenhe papel crucial na transformação da realidade local. Explorando o conhecimento de cada profissional, de suas compreensões e anseios relacionados à sua prática. Diante do exposto procuro ressaltar a relevância desta discussão, para que este torne-se conduta frequente entre os profissionais da educação.

Palavras-chave: Professor Pesquisador. Transformação. Educação de Qualidade.
\end{abstract}

\section{Resumen}

Este artículo tiene como objetivo reflexionar sobre la importancia del papel del profesor investigador, con el fin de resaltar el compromiso del profesor como agente de investigación, por lo que es esencial para él desempeñar un papel crucial en la transformación de la realidad local. Explorando el conocimiento de cada profesional, sus comprensiones y ansiedades relacionadas con su práctica. Dado lo anterior, trato de enfatizar la relevancia de esta discusión, para que se convierta en una conducta frecuente entre los profesionales de la educación.

Palabras clave: Profesor investigador. Transformación Educación de calidad.

\begin{abstract}
This article aims to make reflections on the importance of the role of the researcher teacher, in order to highlight the engagement of the teacher as a research agent, making it essential for him to play a crucial role in the transformation of local reality. Exploring the knowledge of each professional, their understandings and anxieties related to their practice. Given the above I try to emphasize the relevance of this discussion, so that it becomes frequent conduct among education professionals.

Keywords: Research. Transformation. Quality education.
\end{abstract}

1 Aluna do Programa de Pós-Graduação em Educação da Universidade Federal do Pampa - UNIPAMPA / Campus Jaguarão. carlatormam@gmail.com

2 Professora permanente do Programa de Pós-Graduação em Educação da Universidade Federal do Pampa UNIPAMPA/ Campus Jaguarão. paulaselbach@unipampa.edu.br.

\section{Introdução}

Este artigo busca criar um diálogo sobre a importância da pesquisa na vida do professor, tratando tanto da sua forma mais específica voltada ao seu dia-a-dia, como quando participa da construção dos documentos norteadores das escolas. Dentre as suas várias funções, enquanto professor, estão a pesquisa e o quanto esta é responsável pelo seu crescimento profissional buscando sempre melhorias e qualidade ao seu trabalho.

A pesquisa torna-se para o professor espaço de aprendizagem e criticidade, assim se constrói um bom professor através de suas inquietudes e questionamentos. 


\section{A importância do professor pesquisador}

Tratar da importância dos professores enquanto agentes de pesquisa no decorrer de todos os processos escolares, dentre eles a revisão da proposta pedagógica das escolas, tem emergido como fundamental na carreira de todo o professor. O autor Pedro Demo (2015) reserva um capítulo de seu livro para tratar do professor enquanto pesquisador, destacando o que seriam os cinco desafios dos educadores no papel de pesquisadores no contexto educativo, nas palavras do autor são eles: Demo (2015, p.47) "1- (Re) construir projeto pedagógico próprio, 2- $(\mathrm{Re})$ construir textos científicos próprios, 3- $(\mathrm{Re})$ fazer material didático próprio, 4- Inovar a prática didática, 5- recuperar constantemente a competência”. De pronto lanço nossa discussão ao item de número um, que segundo o autor destaca o fazer pesquisador do professor para que possa construir a proposta pedagógica. Para ele, Demo (2015, p.47) "Em vez de falar como mero porta-voz de teorias alheias, ou de apresentar-se como mero discípulo, precisa comparecer com a proposta própria, elaborada e sempre reelaborada".

O engajamento do professor é peça fundamental para que de fato este obtenha o papel crucial na transformação da realidade local, explorando o conhecimento de cada profissional, de suas compreensões e anseios relacionados à sua prática, podendo assim estar refletida na proposta pedagógica da sua comunidade.

Para Demo (2015) é fundamental que o professor seja também um pesquisador, para que possa atuar e modificar o meio ao qual está inserido, não como um profissional da pesquisa, mas sim como um profissional da educação. Nas palavras do autor, Demo (2015, p. 47) “Assim como um engenheiro civil precisa saber coordenar a construção de um prédio residencial, ou um cirurgião realizar com perícia uma cirurgia, deve o professor manejar com virtuosismo inequívoco sua proposta pedagógica, com pé e cabeça, começo, meio e fim.”

Esse destaque do autor vai de encontro com a importância da pesquisa para o fazer pedagógico de forma que a participação dos professores nas escolas, torna-se fundamental para a construção da proposta pedagógica na comunidade ao qual está inserido, onde a pesquisa se finda, porém o ganho permanece no cotidiano da comunidade escolar.

É necessário que a escola tenha muito claro seus objetivos e metas, permitindo que membros da comunidade escolar tenham voz e que seus interesses estejam representados dentro das pesquisas. Quando se trabalha com diversas pessoas, é de fundamental importância o trabalho em grupo, as troca de experiências, conhecimentos, sempre priorizando o diálogo para formar um processo de definições para o espaço, para que o mesmo possa caminhar de forma organizada, competente. Veiga (2013) trata da relevância 
de criar situações de aprendizados entre os professores na elaboração do fazer pedagógico, para autora:

O ponto que nos interessa reforçar é que a escola não tem mais possibilidade de ser dirigida de cima para baixo e na ótica do poder centralizador que dita às normas e exerce o controle burocrático. A luta da escola é para a descentralização em busca de sua autonomia e qualidade. (VEIGA, 2013. pp.15)

Quando o professor realiza o seu trabalho entrelaçado com a pesquisa, muitas aprendizagens e trocas vão surgindo, construindo um processo seguro e bem estruturado para a escola. É necessário atentarmos para algumas questões de representatividade dos sujeitos nestas propostas, para que os processos educativos sejam de fatos transformadores de realidades, Rossi (2005) aborda com maestria essa questão, Rossi (2005, p. 74) "A escola contribui, em determinados momentos históricos, para a formação de identidades sociais e individuais especificas, de saberes docentes e discentes que não ocultam nem neutralizam as lutas e os conflitos sociais". Precisamos organizar estes processos aos saberes que queremos que representem a comunidade escolar, para a autora, Rossi $(2005$, p. 74) "Saberes que nos ajudam, de forma desigual em diferentes grupos e sociedades, a transformar o mundo em que vivemos". Todos devem participar, para que todos estejam a par de cada um dos itens expressos na proposta pedagógica da escola. Para Gadotti (2000):

Todo o projeto supõe rupturas com o presente e promessas para o futuro. Projetar significa tentar quebrar um estado confortável para arriscar-se, atravessar um período de instabilidade e buscar uma nova estabilidade em função da promessa que cada projeto contém de estado melhor do que o presente. Um projeto educativo pode ser tomado como promessa frente a determinadas rupturas. As promessas tornam visíveis os campos de ação possível, comprometendo seus atores e autores. (GADOTTI, 2000, pp.38).

Um bom exemplo da importância deste professor pesquisador e participativo das ações dentro da escola, esta em sua participação nos documentos norteadores das escolas como Projeto Político-Pedagógico e Regimento Escolar. (ROSSI, 205, p.73) "Educar (ensinar) supõe um desenvolvimento pessoal e intelectual desejável, uma formação continuada dos educadores, sem falar o projeto pedagógico socializado na comunidade escolar".

Elaborar os documentos norteadores da escola como Projeto Político-Pedagógico e Regimento Escolar, é dar voz e rosto aos interesses e metas da instituição e sua comunidade. Algumas medidas precisam ser tomadas para que a comunidade possa encontrar espaço de participação nestas atividades, incluindo todos os que trabalham na escola. Barroso (2013, p.40) "A necessidade de envolver na gestão todos os que trabalham na escola exige normas e práticas que promovam uma gestão participativa e uma cultura democrática, quer pela valorização de formas de participação representativa, quer principalmente diferenciado e coletivo de funções de gestão". 
Quando tratamos da importância do Projeto Político-Pedagógico, Ilma Passos Veiga (2012) destaca em sua obra que este documento não é meramente burocrático, acúmulos de propostas e intenções com o fim de cumprir com exigências legais, mas que este deva fazer parte do dia-a-dia da escola. Para a autora:

O projeto busca um rumo, uma direção. É uma ação intencional, com um sentido explícito, com um compromisso definido coletivamente. Por isso, todo projeto pedagógico da escola é, também, um projeto político por estar intimamente articulado ao compromisso sociopolítico com os interesses reais e coletivos da população majoritária. É político no sentido de compromisso com a formação do cidadão para um tipo de sociedade. (VEIGA, 2012, pp.15).

A Lei de Diretrizes e Bases da Educação prevê que todos os profissionais da educação devam ter efetiva participação na proposta pedagógica da escola, salientando a participação e a importância dos representantes do Conselho Escolar neste processo. Compreender a gestão democrática é compreender que esta não é apenas uma sugestão, e sim o entendimento fundamental de funcionamento e democratização da vida escolar.

O Plano Nacional de Educação traz como Meta 19 a seguinte orientação:

Meta 19: assegurar condições, no prazo de dois anos, para a efetivação da gestão democrática da educação, associada a critérios técnicos de mérito e desempenho e à consulta pública à comunidade escolar, no âmbito das escolas públicas, prevendo recursos e apoio técnico da União para tanto. (BRASIL, PNE, 2014, pp.59).

$\mathrm{Na}$ escola a gestão democrática caracteriza-se pelo papel de seus agentes em identificar os problemas, deliberar soluções e indicar as suas prioridades e necessidades existentes dentro da comunidade escolar, sempre planejando as suas ações.

\section{Conclusão}

Após esta breve discussão sobre a importância e o papel do professor pesquisador, espero ter explicitado o que considero importante para a Educação enquanto seus sujeitos agem de forma a serem agentes de transformação da realidade a qual estão inseridos a partir da pesquisa.

Destacando a importância da construção, a partir da pesquisa, dos documentos norteadores da educação, mais precisamente das instituições de ensino, evidenciando a importância da construção coletiva quando no referimos a identidade de cada espaço educacional. 


\section{Referências}

BARROSO, João. O reforço da autonomia das escolas e a flexibilidade da gestão escolar em Portugal. In: Gestão democrática da educação: atuais tendências, novos desafios/Naura Syria Carapeto Ferreira, (org). -8.ed.-São Paulo: Cortez, 2013.

BRASIL. Plano Nacional de Educação - PNE. Ministério da Educação: Secretaria de Articulação com os Sistemas de Ensino (MEC/SASE), 2014. Disponível em:

<http://pne.mec.gov.br/images/pdf/pne_conhecendo_20_metas.pdf >. Acessado em: Março/2018

BRASIL. Lei de Diretrizes e Bases da Educação Nacional. Casa Civil. Lei no 9394. Estabelece as diretrizes e bases da educação nacional. Projeto de Lei. Brasília/1996.

DEMO, Pedro. Educar pela Pesquisa. Campinas, SP: Autores Associados, 2015.

GADOTTI, Moacir. Perspectivas Atuais da Educação. Porto Alegre: Artmed, 2000.

ROSSI, Vera Lúcia de. Gestão do Projeto Político-Pedagógico: Entre corações e Mentes. São Paulo: Moderna, 2005.

VEIGA, Ilma Passos Alencastro. Projeto Político-Pedagógico da Escola: Uma Construção Possível. Campinas: Papirus,2013.

Educação básica: Projeto político-pedagógico; Educação superior: Projeto político-pedagógico/Ilma Passos Alencastro Veiga. $6^{\circ}$ ed. - Campinas, SP: Papirus, 2012. (Coleção Magistério: Formação e Trabalho Pedagógico). 